Burbott, A.J. and W.D. Loomis. 1967. Effects of light and temperature on the monoterpenes of peppermint. Plant Physiol. 42:20-28.

Chialva, F., G. Gabri, P.A.P. Liddle, and F. Ulian. 1982. Qualitative evaluation of aromatic herbs by direct head space $(\mathrm{GC})^{2}$ analysis. Applications of the method and comparison with the traditional analysis of essential oils, p. 183-195. In: N. Margaris, A. Koedam, and D. Vokou (eds.). Aromatic plants-basic and applied aspect. Martinus Nijhoff, Netherlands.

Croteau, R. 1986. Biochemistry of monoterpenes and sesquiterpenes of the essential oils, p. 81-133. In: L.E. Craker and J.E. Simon (eds.). Herbs, spices, and medicinal plants: Recent advances in botany, horticulture, and pharmacology, vol. 1. Oryx Press, Phoenix, Ariz.

Godefroot, M., P. Sandra, and M. Verzele. 1981. New method for quantitative essential oil analysis. J. Chrom. 203:325-335.

Greenhalgh, P. 1982. Production, trade and markets for culinary herbs. p. 139-166. In: C.K. Atal and B.M. Kapoor (eds.). Cultivation and utilization of aromatic plants. Regional research laboratory, JammuTawi, India.

Guenther, E. 1972. The production of essential oils, p. 87: In: E. Guenther (ed.). The essential oils. Krieger Publ. Co., Malabar, Fla.
Heath, H.B. 1981. Source book of flavors. AVI, Westport, Conn.

Kasting, R., J. Anderson, and E. van Sydow. 1972. Volatile constituents in leaves of parsley. Phytochemistry 11:2277-2282.

Lawrence, B.M., J.W. Hogg, S.J. Terhune, and N. Pichitakul. 1972. Essential oils and their constituents. IX. The oils of Ocimum sanctum and Ocimum basilicum from Thailand. Flavor Ind. Jan. p. 47-49. Lickens, S. and G. Nickerson. 1964. New method for essential oil analysis. Proc. Amer. Soc. Brew. Chem. p. 5-10.

Simon, J.E., A.F. Chadwick, and L.E. Craker. 1984. Basil. Herbs: An indexed bibliography, 1971-1980. The scientific literature on selected herbs, and aromatic and medicinal plants of the temperate zone. Archon Books, Hamden, Conn. p. 7-9.

Takeoka, G., S. Ebeler, and W. Jennings. 1985. Capillary gas chromatographic analysis of volatile flavor compounds, p. 96-108. American Chemical Society Symp. Ser. 289, Amer. Chem. Soc., Washington, D.C.

Werker, E., E. Putievsky, and U. Ravid. 1985. The essential oils and glandular hairs in different chemotypes of Origanun vulgare L. Ann. Bot. 55:793-801.

J. AMER. SOC. HORT. SCI. 115(3):462-467. 1990.

\title{
Seasonal Changes of Membrane Lipids in Apple Shoots
}

\author{
Shiow Y. Wang and Miklos Faust \\ Fruit Laboratory, Beltsville Agricultural Research Center, Agricultural Research Service, U.S. \\ Dept. of Agriculture, Beltsville, MD 20705 \\ Additional index words. Malus domestica, fatty acids, glycolipid, phospholipid, sterols
}

\begin{abstract}
Composition changes in galactolipids, phospholipids, and sterols in apple shoots (Malus domestica Borkh. cv. Red Delicious) from August to April were determined. The predominant fatty acids in the membrane lipids of apple shoots were palmitic acid (C16:0), linoleic acid (C18:2), and linolenic acid (C18:3). The major galactolipid components in apple shoots were monogalactosyl diglyceride (MGDG) and digalactosyl diglyceride (DGDG). The amount of MGDG and DGDG increased from autumn to spring. Galactolipids contained highly unsaturated fatty adds, mainly linoleic (18:2) and linolenic (18:3) acid. The major individual phospholipids were phosphatidylcholine (PC) and phosphatidylethaeolamine (PE). $\beta$-Sitosterol and sitosteryl ester were the predominant sterols. The phloem contained higher amounts of galactolipids, phospholipids, and sterols than did the xylem tissue. There was a significant increase in the content of galactolipids and phospholipids and onsaturation of their fatty acids during cold acclimation. A decrease in the ratio of free sterols to phospholipids also occurred in apple shoots toward cold winter months. Composition changes in galactolipids, phospholipids, and sterols that were associated with growth cessation, defoliation and cold acclimation from fall to winter, were mostly reversed foilowing deacclimation in spring.
\end{abstract}

Growth temperature has a major influence on membrane fatty acid composition and unsaturation. Changes in composition of the fatty acid components of membrane lipids are important in the acclimation of most types of plants (Martin et al., 1976). Most deciduous fruit trees growing in temperate climates develop some degree of cold hardiness with the onset of winter. Many plants capable of cold hardening exhibit an increase in lipid unsaturation (Willemot, 1975) and an increase in the level of phospholipids during hardening (de la Roche, 1979; Sikorska and Kacperska-Palacz, 1979; Siminovitch et al., 1968; Willemot, 1975). This change is probably one of several factors in maintaining membrane permeability and in regulating the activ-

\footnotetext{
Received for publication 9 Jan. 1989. We thank Amy L. Jordan for technical assistance. Use of a company or product name does not constitute an endorsement by USDA nor imply approval to the exclusion of other suitable products. The cost of publishing this paper was defrayed in part by the payment of page charges. Under postal regulations, this paper therefore must be hereby marked advertisement solely to indicate this fact.
}

ity of membrane-associated enzymes (Cronan and Gelmann, 1975; Raison, 1985).

Sterols play a vital role during the growth and development of higher plants (Garg and Paleg, 1986). Sterols in plants are considered to be structural components of cell membranes and they play a role in membrane permeability and serve as membrane stabilizers (Heftman, 1971). The ratio of sterols to phospholipids decreased with cold hardiness. Decreases in phospholipid content, degree of unsaturation in phospholipid fatty acids, and membrane fluidity were observed in the plasma membrane of the bark of mulberry trees during cold deacclimation. The sterol to phospholipid ratio increased with decreasing cold hardiness (Yoshida, 1986). However, the degree of unsaturation in the lipids of bark of black locust 'trees does not change during the year. Hardening of the bark cells during winter is correlated with increased total phospholipid levels (Siminovitch et al., 1975). Despite numerous investigations carried out on this subject, there is little information about changes in membrane lipids and their quantitative relationships during the growing season of decid- 
uous fruit trees. It is important to investigate changes of membrane lipids in apple trees during dormancy and budbreak to determine if these changes are associated with acclimation and deacclimation and if these events can be better regulated. The aim of the present study was to investigate whether the seasonal fluctuation of growing temperatures induces lipid changes in the shoots of apple trees and to determine whether the acyl chains of phospholipids are affected during cold acclimation from autumn to mid-winter and if they are reversed during deacclimation in spring.

\section{Material and Methods}

Plant material. Twenty 10-year-old 'Delicious' apple trees planted at the Agricultural Research Center in Beltsville, Md., were used in this study. Twenty newly produced shoots (1-yearold branches) were randomly collected from each tree between 8:30 and 9:30 AM on the 15th day of each month from August to March. Samples were also collected on 5 and 22 Apr. Phloem (bark) and xylem (wood) from these shoots (buds removed) were separated and cut into thin slices, frozen, and used for lipid analysis.

Extraction, fractionation, and analysis of lipids. Lipids were extracted, fractionated, and analyzed according to procedures described by Wang and Faust (1988). Phloem and xylem were extracted with isopropanol containing $4 \mu \mathrm{g}$ 2,6-di-t-butyl-4 methylphenol (BHT)/ml. Total lipids were separated into neutral, glyco-, and phospholipid fractions by silicic acid column chromatography on 100- to 200-mesh Bio Sil A (Bio Rad Laboratories, Richmond, Calif.). The glycolipid and phospholipid fractions were further separated by thin-layer chromatography (TLC) on $20 \times 20-\mathrm{cm}^{2}$ glass plates precoated with a $250 \mu \mathrm{m}$ thickness of silica gel 60 (EM Reagents, Darmstadt, F.R.G.) in solvent systems consisting of 100 acetone : 2 acetic acid : 1 water (by volume) and 85 chloroform : 15 methanol : 10 acetic acid : 3.5 water (by volume), respectively. Individual galactolipids and phospholipids were identified by cochromatography with authentic standards (Sigma, St. Louis, and Supelco, Bellefonte, $\mathrm{Pa}$.) and by detection with spray reagents specific for hexose sugars or phosphate. Individual lipid bands were scraped. off and eluted in 2 chloroform : 1 methanol (v/v). Total fatty acids esterified to polar lipids from phloem and xylem tissues were derivatized to fatty acid methyl esters (FAME) for flame ionization detection-gas chromatography (FID-GC) analysis
(Wang and Faust, 1988). n-Heptadecanoic acid was included in all samples as an internal standard, and methyl heptadecanoate was used as an external standard. Individual FAME were identified by comparison of retention times with those of authentic standards (Supelco). This tentative identification of the major polar lipid fatty acids was corroborated by further analysis of the FAME by gas chromatography-mass spectrometry (GC-MS) (Wang et al., 1988).

Free and esterified sterols in the neutral lipid fraction from phloem and xylem were separated by TLC on silica gel plates (250 $\mu \mathrm{m}$ thick, Merck G 60). A known amount of cholesterol and cholesteryl myristate was included in all samples in internal standards (endogenous levels of cholesterol and cholesteryl esters were negligible). TLC plates were developed in a solvent mix of 80 hexane : 20 ethyl acetate : 2 formic acid (by volume). Spots corresponding to free sterols and steryl esters were identified by spraying with $\mathrm{FeCl}_{3}$ reagent. Free sterols and steryl esters were scraped and eluted with $3 \mathrm{ml} 2$ chloroform : 1 methanol (v/v) plus $4 \mu \mathrm{g}$ BHT/ml. After adding $1 \mathrm{ml} 0.8 \%$ $\mathrm{NaCI}(\mathrm{w} / \mathrm{v})$, vortexing under $\mathrm{N}_{2}$, and centrifuging, the $\mathrm{CHCl}_{3}$ phase containing free sterols and steryl esters was evaporated to dryness under $\mathrm{N}_{2}$. Free sterols were dissolved in isooctane before GC analysis. Steryl esters were saponified in $1 \mathrm{M} \mathrm{KOH}$ in $85 \%$ ethanol for $1 \mathrm{hr}$ at $80 \mathrm{C}$ (under $\mathrm{N}_{2}$ ). After cooling and adding 1 volume of $\mathrm{H}_{2} \mathrm{O}$, free sterols were extracted with hexane. Samples were evaporated to dryness under $\mathrm{N}_{2}$ and redissolved in isooctane for GC analysis. Sterol composition was determined by FID-GC (Wang and Faust, 1988) and further confirmed by GC-MS (Wang et al., 1988).

Data were analyzed with analysis of variance procedures. All values are the means of three replicate samples. Standard errors of means are reported.

\section{Results and Discussion}

Galactolipids. The phloem and xylem contained monogalactosyl diglyceride (MGDG) and digalactosyl diglyceride (DGDG). The phloem contained a higher amount of the galactolipids than xylem tissue (Tables 1 and 2). MGDG was the major galactolipid, with about twice the amount of DGDG. The amount of MGDG and DGDG showed a continuous increase from August to April, especially toward spring (Tables 1 and 2). The increase in MGDG and DGDG may be associated with the development of chloroplasts in outer layers of apple bark, which turned green-

Table 1. Seasonal changes ( $\mathrm{mg} \cdot \mathrm{g}^{-1}$ dry weight) of glycolipids and phospholipids in the phloem of apple trees.,

\begin{tabular}{|c|c|c|c|c|c|c|}
\hline \multirow[b]{2}{*}{ Month } & \multicolumn{2}{|c|}{ Glycolipid } & \multicolumn{4}{|c|}{ Phospholipid } \\
\hline & MGDG & DGDG & $\mathrm{PC}$ & $P G$ & PE & PI \\
\hline $\begin{array}{l}\text { Aug. } \\
\text { Sept. } \\
\text { Oct. } \\
\text { Nov. } \\
\text { Dec. } \\
\text { Jan. } \\
\text { Feb. } \\
\text { Mar. } \\
\text { Apr. (carly) } \\
\text { Apr. (late) }\end{array}$ & $\begin{array}{l}89 \pm 2 \\
149 \pm 5 \\
164 \pm 7 \\
162 \pm 5 \\
164 \pm 6 \\
178 \pm 5 \\
190 \pm 6 \\
182 \pm 7 \\
243 \pm 13 \\
333 \pm 15\end{array}$ & $\begin{array}{r}42 \pm 6 \\
56 \pm 8 \\
61 \pm 5 \\
105 \pm 5 \\
107 \pm 8 \\
114 \pm 3 \\
114 \pm 3 \\
125 \pm 5 \\
133 \pm 2 \\
133 \pm 3\end{array}$ & $\begin{array}{l}370 \pm 18 \\
480 \pm 11 \\
504 \pm 10 \\
586 \pm 23 \\
620 \pm 15 \\
873 \pm 48 \\
981 \pm 52 \\
824 \pm 38 \\
630 \pm 27 \\
420 \pm 22\end{array}$ & $\begin{array}{r}43 \pm 3 \\
50 \pm 6 \\
55 \pm 7 \\
71 \pm 4 \\
73 \pm 8 \\
134 \pm 9 \\
112 \pm 8 \\
101 \pm 5 \\
88 \pm 6 \\
60 \pm 4 \\
\end{array}$ & $\begin{array}{l}127 \pm 6 \\
142 \pm 8 \\
186 \pm 11 \\
263 \pm 10 \\
320 \pm 17 \\
408 \pm 12 \\
410 \pm 18 \\
399 \pm 16 \\
318 \pm 23 \\
202 \pm 11\end{array}$ & $\begin{aligned} & 71 \pm 5 \\
& 87 \pm 4 \\
& 92 \pm 6 \\
& 97 \pm 7 \\
& 98 \pm 2 \\
& 156 \pm 10 \\
& 176 \pm 8 \\
& 171 \pm 7 \\
& 123 \pm 5 \\
& 111 \pm 4 \\
&\end{aligned}$ \\
\hline
\end{tabular}

${ }^{\mathrm{z}}$ Abbreviations: MGDG, monogalactosyl diglyceride; DGDG, digalactosyl diglyceride; PC, phosphatidylcholine; PE, phosphatidylethanolamine; PG, phosphatidylglycerol; PI, phosphatidylinositol.

${ }^{\mathrm{y}}$ Means of three replicates \pm SE. 
Table 2. Seasonal changes $\left(\mathrm{mg} \cdot \mathrm{g}^{-1}\right.$ dry weight) of glycolipids and phospholipids in the xylem of apple trees. ${ }^{z, y}$

\begin{tabular}{lcccccc}
\hline \hline & \multicolumn{2}{c}{ Glycolipid } & \multicolumn{4}{c}{ Phospholipid } \\
\cline { 2 - 5 } \cline { 5 - 7 } Month & MGDG & DGDG & PC & PG & PE & PI \\
\hline Aug. & $18 \pm 2$ & $14 \pm 2$ & $141 \pm 9$ & $11 \pm 1$ & $40 \pm 2$ & $46 \pm 2$ \\
Sept. & $23 \pm 3$ & $15 \pm 1$ & $146 \pm 10$ & $17 \pm 2$ & $54 \pm 3$ & $51 \pm 1$ \\
Oct. & $23 \pm 3$ & $16 \pm 3$ & $177 \pm 7$ & $17 \pm 2$ & $68 \pm 4$ & $60 \pm 3$ \\
Nov. & $32 \pm 4$ & $18 \pm 2$ & $308 \pm 12$ & $29 \pm 3$ & $135 \pm 8$ & $66 \pm 4$ \\
Dec. & $32 \pm 7$ & $39 \pm 3$ & $341 \pm 10$ & $33 \pm 4$ & $138 \pm 4$ & $76 \pm 2$ \\
Jan. & $74 \pm 4$ & $42 \pm 2$ & $361 \pm 11$ & $39 \pm 2$ & $200 \pm 10$ & $80 \pm 3$ \\
Feb. & $78 \pm 6$ & $48 \pm 1$ & $404 \pm 18$ & $47 \pm 4$ & $246 \pm 13$ & $96 \pm 6$ \\
Mar. & $79 \pm 8$ & $48 \pm 2$ & $335 \pm 14$ & $29 \pm 3$ & $179 \pm 8$ & $78 \pm 4$ \\
Apr. (early) & $77 \pm 3$ & $62 \pm 4$ & $175 \pm 4$ & $18 \pm 2$ & $85 \pm 2$ & $44 \pm 2$ \\
Apr. (late) & $90 \pm 5$ & $62 \pm 2$ & $159 \pm 7$ & $21 \pm 1$ & $64 \pm 3$ & $45 \pm 3$ \\
\hline
\end{tabular}

${ }^{\mathrm{z}}$ Abbreviations: MGDG, monogalactosyl diglyceride; DGDG, digalactosyl diglyceride; PC, phosphatidylcholine; PE, phosphatidylethanolamine; PG, phosphatidylglycerol; PI, phosphatidylinositol.

${ }^{\mathrm{y}}$ Mean of three replicates $\pm \mathrm{SE}$.

ish toward spring. Analysis of the fatty acid composition of major lipid classes in the phloem and xylem tissues showed substantial changes in the proportion of certain fatty acids during this period (Figs. 1 and 2). The C18 unsaturated fatty acids of galactolipids underwent major changes in content in phloem and xylem. Galactolipids contained highly unsaturated fatty acids, mainly linoleic (18:2) and linolenic (18:3) acids. The concentration of linolenic acid was higher in phloem than that observed in the xylem tissue.

The fatty acid profiles of MGDG from phloem tissue showed that the linolenic acid (18:3) content was relatively high. It increased from $62 \%$ in August to a plateau at $\approx 80 \%$ in December, remaining constant thereafter. The proportion of other fatty acids [e.g., palmitic acid (16:0) and stearic acid (18:1)] was $<10 \%$. The proportion of linoleic acid in phloem tissue was $\approx 12 \%$, but decreased slightly by December and then increased to $18 \%$ in February. Xylem tissue contained a higher proportion of $18: 2(40 \%$ to $60 \%)$ and $18: 3(25 \%$ to $45 \%)$. The relative percentage of linolenic acid (18:3) remained almost constant from August to February, then decreased toward spring, along

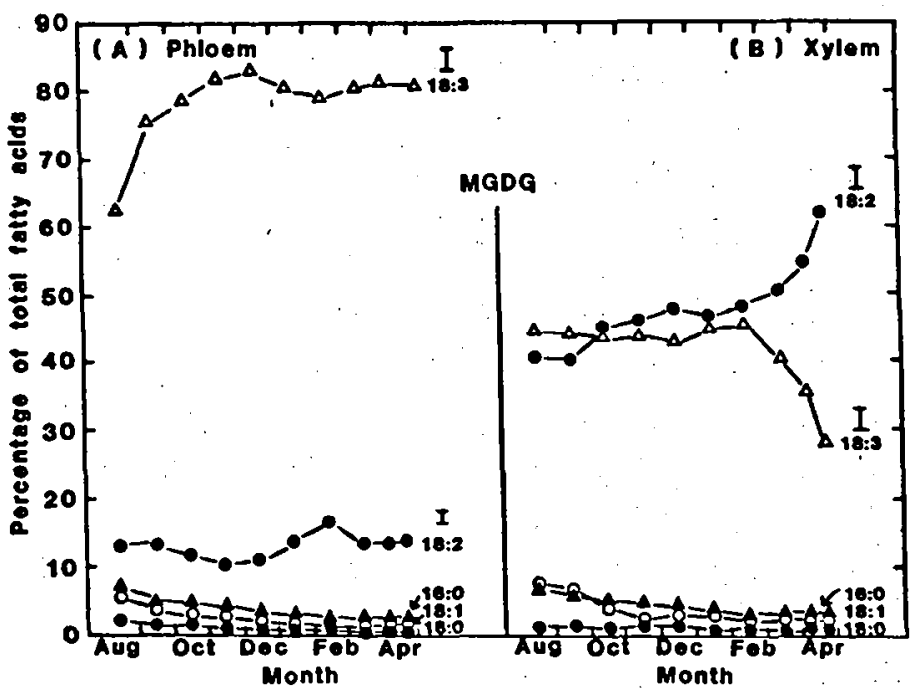

Fig. 1. Changes of fatty acid composition (weight percentage of total) of monogalactosyl diglyceride (MGDG) in apple shoots from August to April. Data are the means of three replicate samples (LSD, $P=$ $0.05)$.

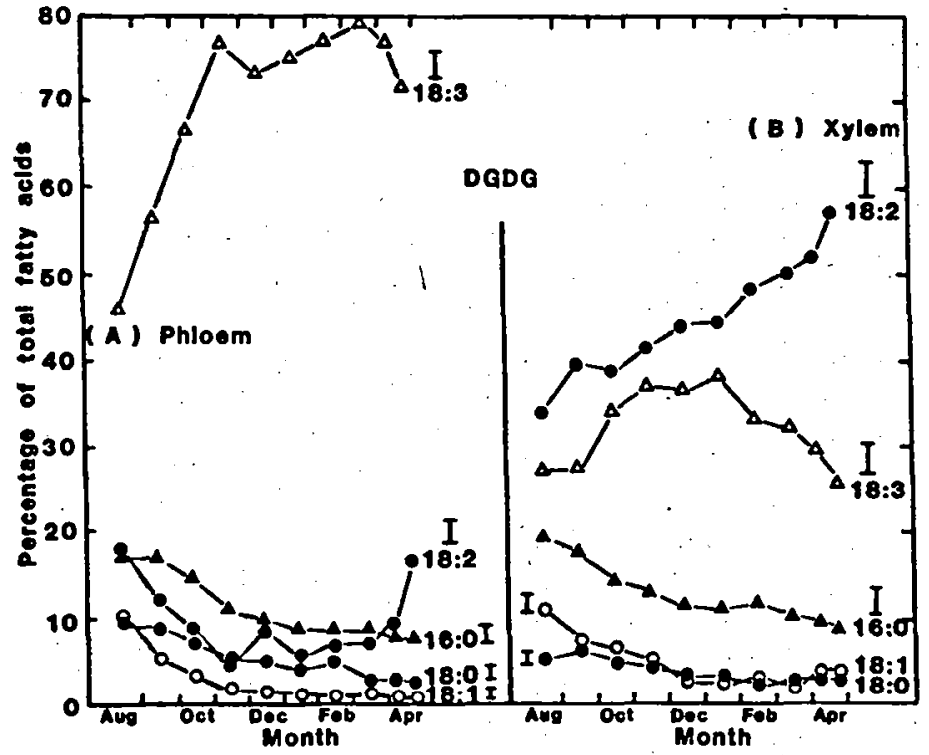

Fig. 2. Changes of fatty acid composition (weight percentage of total) of digalactosyl diglyceride (DGDG) in apple shoots from August to April. Data are the means of three replicate samples (LSD, $P=$ $0.05)$.

with an increase in the relative percentage of linoleic (18:2). A small amount of 16:0, 18:0, and 18:1 was also found in MGDG from xylem tissue.

The fatty acid profiles of DGDG are shown in Fig. 2. Phloem tissue contained a higher proportion of 18:3 acid, whereas xylem contained more 18:2 acid. An increase in the percentage of linolenic acid (18:3) from August to March in phloem tissue was parallel to a decrease of 16:0, 18:0, and 18:1 acids. A decrease of linolenic acid (18:3) and an increase of linoleic acid (18:2) was found in phloem tissue toward spring. The relative percentage of linoleic acid (18:2) of DGDG in xylem tissue increased from August through April, along with a decrease in the relative percentage of 16:0, 18:0, and 18:1 (Fig. 2). Linoleic acid (18:3) in xylem tissue also increased from August to January and then declined (Fig. 2).

The galactolipids, MGDG and DGDG, contained a higher proportion of unsaturated fatty acids than the other lipids. The ratio of unsaturated to saturated fatty acids in MGDG and DGDG 
increased from fall to winter, then declined slightly in spring, except for MGDG in phloem, which remained constant throughout the spring (Fig. 3).

Phospholipid. Phospholipids play a key role in the molecular organization of the membranes (Simon, 1974). The structure and composition of membranes show changes during various physiological and environmental conditions (Muller and Santarius, 1978). The major individual phospholipids that were quantified in apple shoots were phosphatidylinositol (PI), phosphatidylglycerol (PG), phosphatidylcholine (PC), and phosphatidylethanolamine (PE); of these, PC accounted for $56 \%$ of the total. PE and PI, present at levels of $24 \%$. and $13 \%$, respectively, were two other important phospholipids in apple shoots. PG comprised only $\approx 6 \%$ (Tables 1 and 2 ). The total phospholipid extracts from phloem and xylem, which had been cooled (November to March), somewhat exceeded that from warmer seasons. The phloem contained a higher amount of the phospholipid than the xylem (Tables 1 and 2). The phospholipid content of plants is generally known to increase in cold conditions (Kedrowski and Chapin, 1978; Kuiper, 1970). It has been claimed that phospholipid biosynthesis is either stimulated or has a slower turnover during low temperatures (Clarkson et al., 1980; Willemot, 1975).

The changes in fatty acid composition due to seasonal changes differed somewhat between the individual phospholipids. The percentage of individual fatty acids in phloem and xylem tissue are similar (Figs; 4-7). PI contained a relatively higher amount of the saturated fatty acid palmitic acid (16:0) than the other. The amount of $16: 0$ and $18: 3$ in PI did not change significantly from August to March, but linolenic acid (18:3) showed a substantial increase, and palmitic acid (16:0) showed a decrease toward spring. The relative contents of 18:0 and 18:1 decreased, while 18:2 increased during cold acclimation in the winter. Linoleic acid (18:2) in PI decreased toward spring (Fig. 4). The fatty acids of PI were less unsaturated. The ratio of the unsaturated to the corresponding saturated fatty acids in PI remained constant from August to April in phloem and xylem tissues (Fig. 3). PG is largely confined to the chloroplasts and is the only major phospholipid of chloroplast membranes of higher plants (Williams et al., 1983). The amount of chloroplasts is limited in phloem and xylem. This may be the reason for the low PG content in these tissues. PG had the most saturated fatty acid, palmitic acid (16:0), compared to the other phospholipids. The ratio of the unsaturated to saturated fatty acid in PG was very

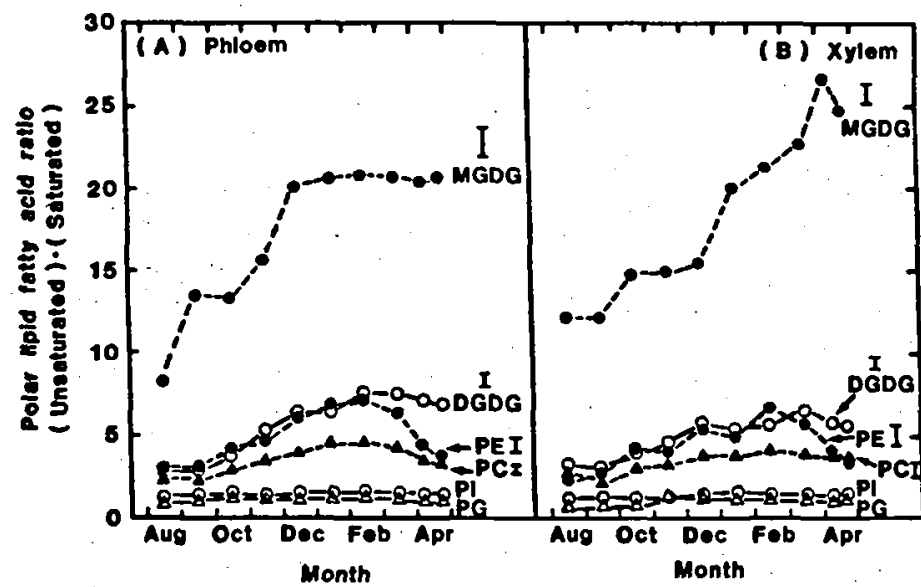

Fig. 3. Changes of fatty acid saturation of apple shoot polar membrane lipids from August to April. Data are the means of three replicate samples (LSD, $P=0.05$ ).

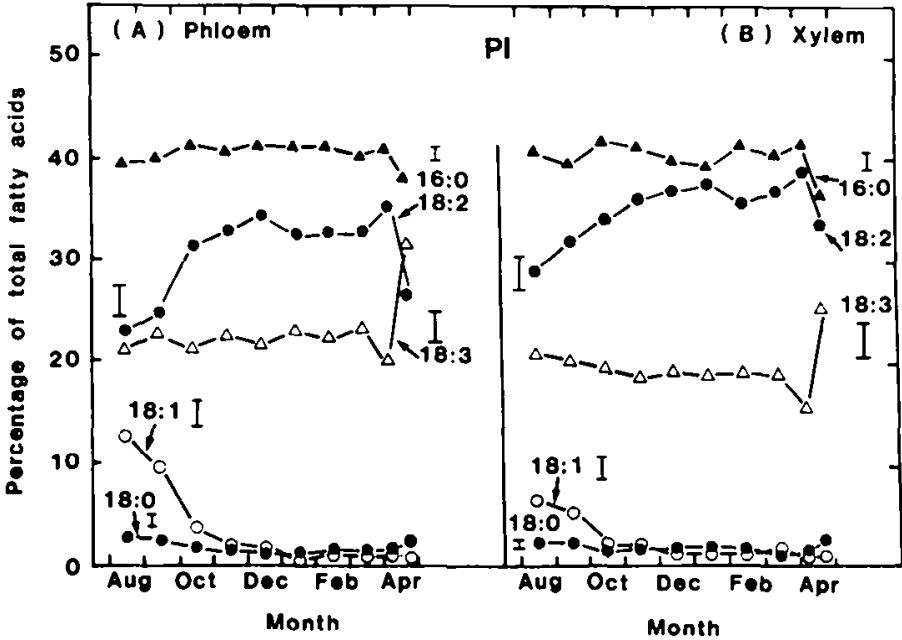

Fig. 4. Changes of fatty acid composition (weight percentage of total) of phosphatidylinositol (PI) in apple shoots from August to April. Data are the means of three replicate samples (LSD, $P=0.05)$.

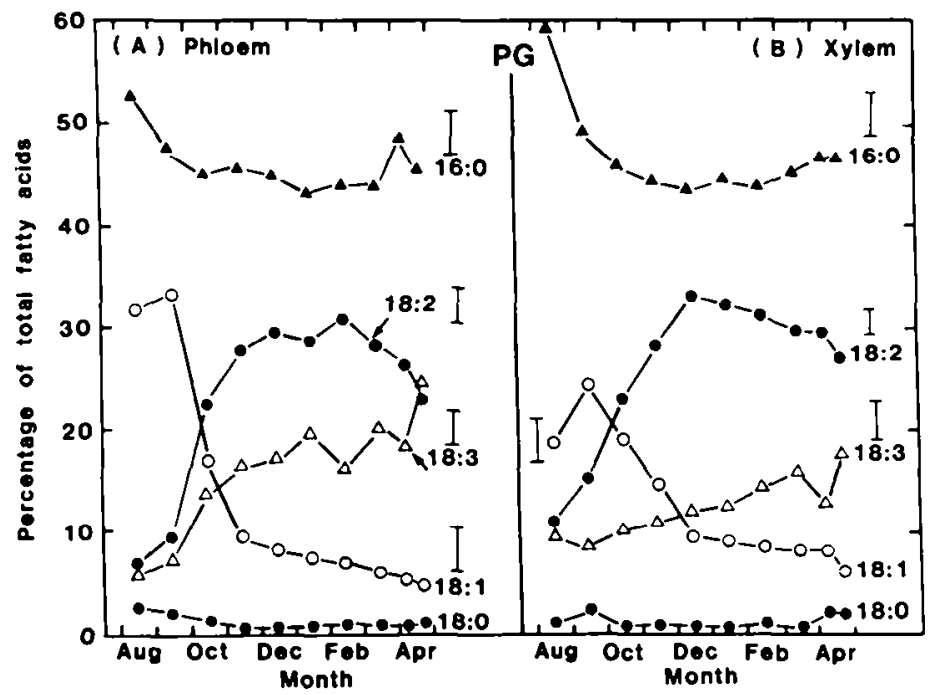

Fig. 5. Changes of fatty acid composition (weight percentage of total) of phosphatidylglycerol (PG) in apple shoots from August to April. Data are the means of three replicate samples (LSD, $P=0.05$ ).

low and stayed constant from August to April. The decrease of 16:0 and 18:1 and the concomitant increases of $18: 2$ and $18: 3$ were seen in PG, indicating the desaturation of 16:0 and 18:1 to $18: 2$ and $18: 3$ (Fig. 5). The decrease of 18:2 toward spring may also have contributed to the increase of 18:3. The presence of a small amount of oleic acid (18:0) in PG remained constant throughout the growing season (Fig. 5). Among the phospholipids, $\mathrm{PC}$ is the most abundant and is very rich in linoleic acid. $\mathrm{PE}$ is about one half as abundant as PC and is also rich in linoleic acid (Tables 1 and 2). Accumulation of PC and PE in membranes during cold temperatures in winter could be part of a common mechanism that results in increased membrane fluidity and prevents the formation of the nonbilayer lipid phase under low winter temperature. Yoshida and Sakai (1973) also observed that the development of hardiness was accompanied by an increase in phospholipids, especially PC and PE (Yoshida, 1974). PC and PE contained mainly palmitic, linoleic, and linolenic acids, which is typical for phospholipids from higher plants. PC and PE had a higher unsaturation degree of fatty acid in the winter, changing, somewhat, toward less unsaturation in the 


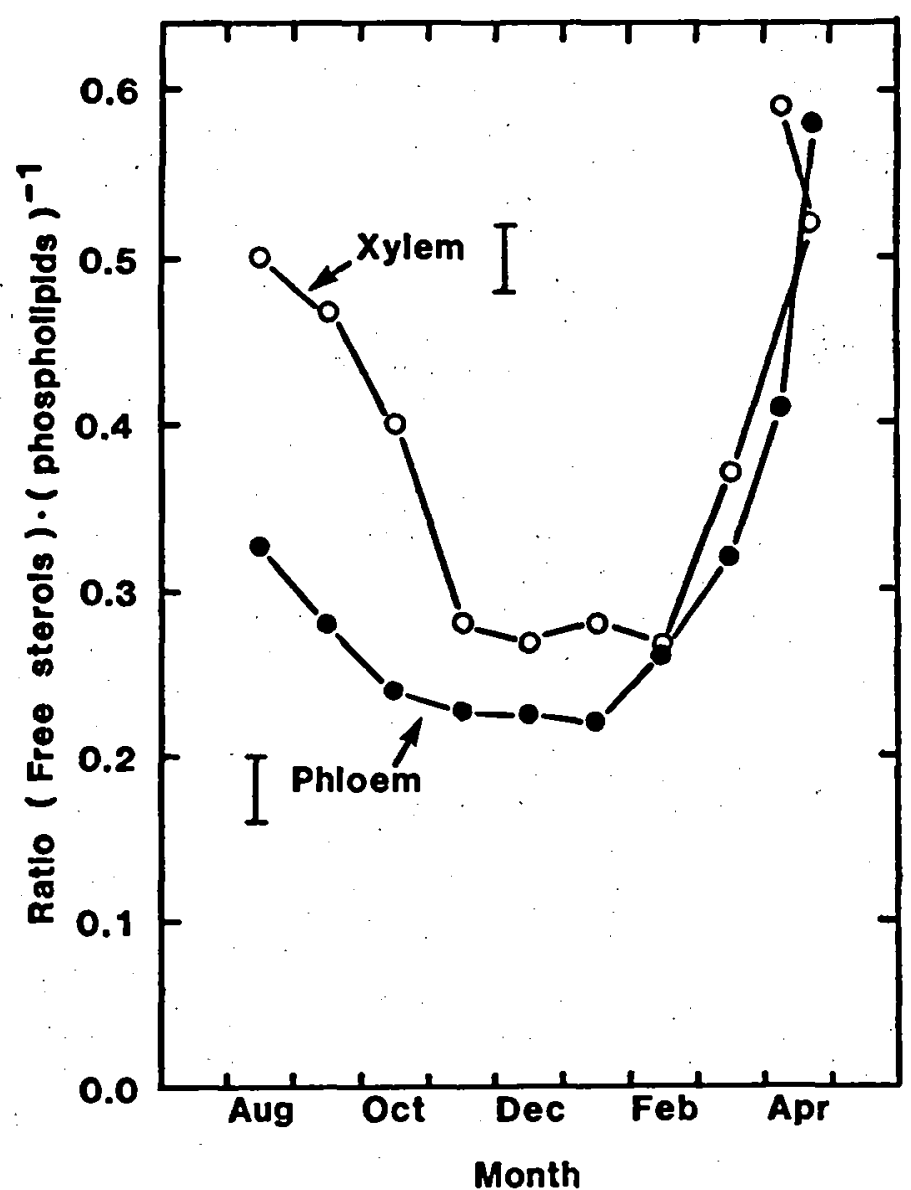

Fig. 9. Changes in the ratio of free sterols to phospholipids in apple shoots from August to April. Data are the means of three replicate samples (LSD, $P=0.05)$.

the unsaturation of the membrane phospholipids is associated with their functional activity, and membrane lipids may be actively metabolized during the growing season. The ratio of sterols to phospholipids decreased in cold winter months, primarily due to the large increase in phospholipids, and resulted in an increase in the fluidity of the membrane. Composition changes in galactolipids, phospholipids, and sterols were observed in association with growth cessation and defoliation from fall to winter and were mostly reversed following deacclimation in spring. Alterations in the composition of membrane lipids can be achieved by applications of the plant bioregulator paclobutrazol (Wang et al., 1988). Therefore, it is quite possible that changes associated with growth of apple shoots can be mediated, at least partly, through changes in membrane lipids that act by affecting the overall physiology of the apple tree.

\section{Literature Cited}

Brockerhof, H. 1974. Model of interaction of polar lipids, cholesterol, and proteins in biological membranes. Lipids 9:645-650.

Clarkson, D.T., KC. Hall, and J.K.M. Roberts. 1980. Phospholipid composition and fatty acid desaturation in the roots of rye during acclimatization of low temperature. Planta 149:464-471.

Cronan, J.E. and E.P. Gelmann. 1975. Physical properties of membrane lipids: Biological relevance and regulation. Bacteriol. Rev. 39:232-256. de la Roche, A.I. 1979. Increase in linolenic acid is not a prerequisite for development of freezing resistance in wheat. Plant Physiol. 63:58.

Garg, V.K. and L.G. Paleg. 1986. Changes in the levels and composition of sterols in different tissues of Lolium temulentum plants during floral development. Physiol. Plant. 68:335-341.

Grunwald, C. 1975. Plant sterols. Annu. Rev. Plant Physiol. 26:209236.

Heftmann, E. 1971. Functions of sterols in plants. Lipids 6:128-133.

Kedrowski, R.A. and F.S. Chapin, III. 1978. Lipid properties of Carex aquatilis from hot spring and permafrost-dominated sites in Alaska: Implication for nutrient requirements. Physiol. Plant. 44:231-237.

Kuiper, P.J.C. 1970. Lipids in alfalfa leaves in relation to cold hardiness. Plant Physiol. 45:684-686.

Martin, C.E., K. Hiramitsu, Y. Kitajima, Y. Nozawa, L. Skriver, and G.A. Thompson, Jr. 1976. Molecular control of membrane properties during temperature acclimation. Fatty acid desaturase regulation of membrane fluidity in acclimating Tetrahymena cells. Biochemistry 15:5218-5227.

Muller, M. and K.A. Santarius. 1978. Changes in chloroplast membrane lipids during adaptation of barley to extreme salinity. Plant Physiol. 62:326-329.

Oldfield, E. and D. Chapman. 1972. Dynamics of lipids in membranes: Heterogeneity and the role of cholesterol. FEBS Lett. 23:285-297.

Raison, J.K. 1985. Alteration in the physical properties and thermal response of membrane lipids: Correlations with acclimation to chilling and high temperature, p. 383-401. In: J.B. St. John, E. Berlin, and P.C. Jackson (eds.). Frontiers of membrane research in agriculture. Rowman-Allanheld, Totowa, N.J.

Sikorska, E. and T. Farkas. 1982. Sterols and frost hardening of winter rape. Physiol. Plant 56:349-352.

Sikorska, E. and A. Kacperska-Palacz. 1979. Phospholipid involvement in frost tolerance. Physiol. Plant. 47:144-150.

Siminovitch, D., B. Rheaume, K. Pomeroy, and M. Lepage. 1968. Phospholipid protein and nucleic acid increase in protoplasm and membrane structure associated with development of extreme freezing resistance in black locust tree cells. Cryobiology 5:205-225.

Siminovitch, D., J. Singh, and I.A. de la Roche. 1975. Studies on membranes in plant cells resistant to extreme freezing. 1. Augmentation of phospholipids and membrane structure without changes in unsaturation of fatty acids during hardening of black locust bark. Cryobiology 12:144-153.

Simon, E.W. 1974. Phospholipids and plant membrane permeability. New Phytol. 73:377-420.

Wang, S.Y. and M. Faust. 1988. Changes of fatty acids and sterols in apple bud during bud break induced by a plant bioregulator, thidiazuron. Physiol. Plant. 72:115-120.

Wang, S.Y., T. Sun, B.D. Whitaker, and M. Faust. 1988. Effect of paclobutrazol on membrane lipids in apple seedlings. Physiol. Plant. 73:560-564.

Willemot, C. 1975. Stimulation of phospholipid biosynthesis during frost hardening of winter wheat. Plant Physiol. 55:356-359.

Williams, J.P., M.U. Khan, and K. Mitchell. 1983. Galactolipid biosynthesis in leaves of 16:3- and 18:3-plants, p. 28-39. In: W.W. Thomson, J.B. Mudd, and M. Gibbs (eds.). Biosynthesis and function of plant lipids. Amer. Soc. Plant Physiol. Symp. in Bot., Riverside, Calif.

Yoshida, S. 1974. Studies on lipid changes associated with frost hardiness in cortex in woody plants. Contrib. Inst. Low Temp. Sci. Ser. B 18:1-43.

Yoshida, S. 1986. Reverse changes in plasma membrane properties upon deacclimation of mulberry trees (Morus bombysis Koidz.). Plant Cell Physiol. 27:83-89.

Yoshida, S. and A. Sakai. 1973. Phospholipid changes associated with the cold hardiness of cortical cells from poplar stem. Plant Cell Physiol. 14:353-359. 